\section{EVOLUTION OF THE ALPHA PARTICLE DRIVEN TOROIDICITY INDUCED ALFVEN MODE}

\section{BY}

Y. WU, R.B. WHITE AND C.Z. CHENG

\author{
APRIL, 1994
}
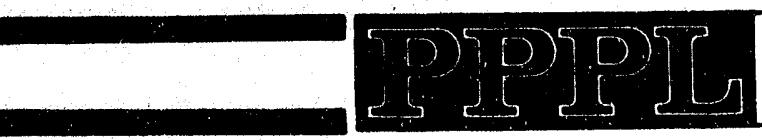

PAINCETON

plabma phraics

LAOEATTOAY

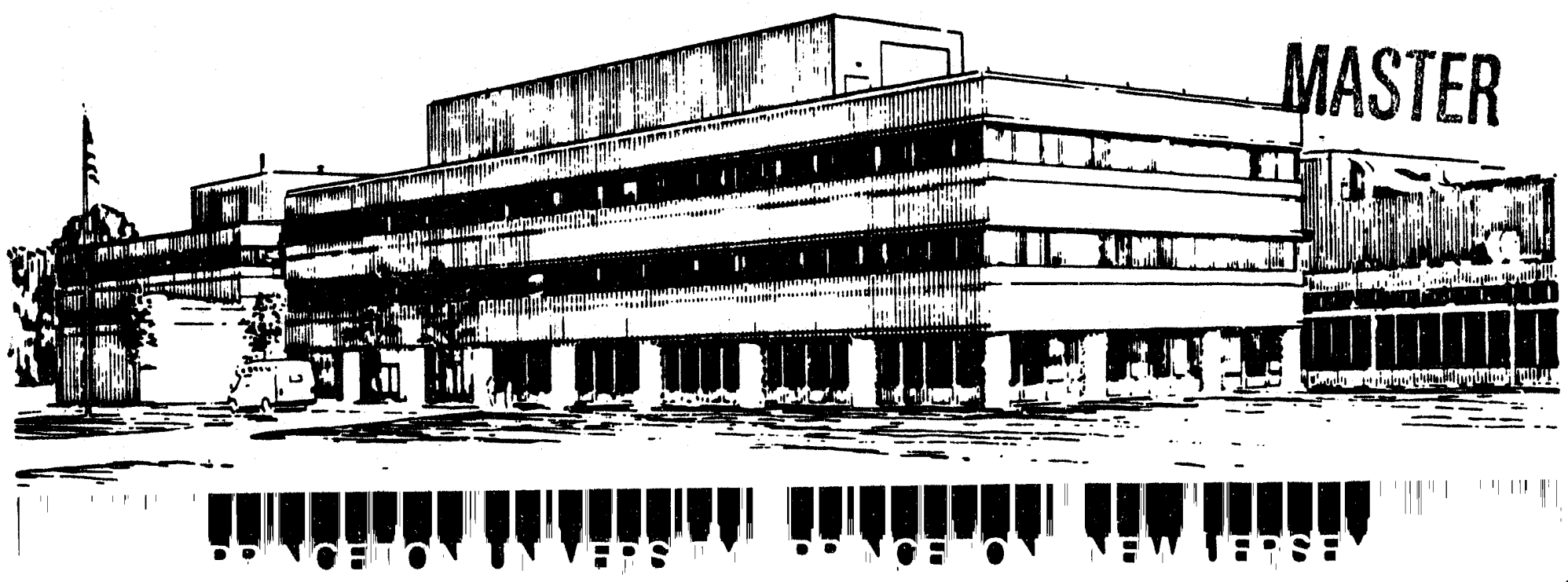




\section{NOTICE}

This report was prepared as an account of work sponsored by an agency of the United States Government. Neither the United States Government nor any agency thereof, nor any of their employees, makes any warranty, express or implied, or assumes any legal liability or responsibility for the accuracy, completeness, or usefulness of any information, apparatus, product, or process disclosed, or represents that its use would not infringe privately owned rights. Reference herein to any specific commercial produce, process, or service by trade name, trademark, manufacturer, or otherwise, does not necessarily constitute or imply its endorsement, recommendation, or favoring by the United States Government or any agency thereof. The views and opinions of authors expressed herein do not necessarily state or reflect those of the United States Government or any agency thereof.

\section{NOTICE}

This report has been reproduced from the best available copy. Available in paper copy and microfiche.

Number of pages in this report: 12

DOE and DOE contractors can obtain copies of this report from:

Office of Scientific and Technical Information

P.O. Box 62

Oak Ridge, TN 37831;

(615) $576-8401$.

This report is publicly available from the:

National Technical Information Service

Department of Commerce

5285 Port Royal Road

Springfield, Virginia 22161

(703) $487-4650$ 


\title{
Evolution of the Alpha Particle Driven Toroidicity Induced Alfvén Mode
}

\author{
Yanlin Wu, R. B. White and C. Z. Cheng \\ Princeton University, Plasma Physics Laboratory, P.O. Box 451 \\ Princeton, New Jersey 08540
}

\begin{abstract}
The interaction of alpha particles with a toroidicity induced Alfvén eigenmode is investigated self-consistently by using a kinetic dispersion relation. All important poloidal harmonics and their radial mode profiles are included. A Hamiltonian guiding center code is used to simulate the alpha particle motion. The simulations include particle orbit width, nonlinear particle dynamics and the effects of the modes on the particles. Modification of the particle distribution leading to mode saturation is observed. There is no significant alpha particle loss.
\end{abstract}

PACS numbers 52.35.Py, 52.35.Bj

In recent years considerable progress has been made in the development of fusion energy, with tokamak experiments rapidly approaching ignition conditions. To sustain ignition in a burning plasma, most of the alphas produced in deuterium-tritium fusion reactions must be confined long enough to heat the bulk plasma. Collective alpha-driven instabilities such as the toroidicity-induced Alfvén eigenmodes (TAE) are of concern for future tokamak devices since they can induce anomalous alpha $\operatorname{losses}^{1-7}$.

In this paper, we study the alpha particle driven TAE instability numerically by following the evolving alpha particle distribution and solving the kinetic dispersion relation, giving the instantaneous mode frequency and growth rate. The simulations include the full nonlinear particle dynamics, particle orbit width and the effects of the mode on the particles. 
We consider an axisymmetric toroidal plasma consisting of a core plasma and a hot ion species. The core plasma is described by ideal magnetohydrodynamics (MHD) and the hot component by the gyro-kinetic equation. Additional damping such as the ion- and electronLandau damping, collisional damping and continuum damping are taken as parameters supplied by other analysis.

Write the perturbed distribution function $\delta f \mathrm{as}^{3}: \delta f=-\xi_{\perp} \cdot \nabla F+\hat{g}$ with $\xi_{\perp}$ the usual fluid displacement vector. The first term on the right-hand side is the adiabatic response, and $\hat{g}$, the non-adiabatic part, satisfies the equation

$\left(-i \omega+v_{\|} \mathbf{b} \cdot \nabla+\mathbf{v}_{d} \cdot \nabla\right) \hat{g}=i 2 F\left(\bar{\omega}-\omega_{*}\right) J\left(\psi_{p}, \theta, \phi\right)$

where $\bar{\omega}=\omega E \partial_{E} \log F, \omega_{*}=(n E / \Omega) \partial_{\psi_{p}} \log F, J\left(\psi_{p}, \theta, \phi\right)=(1-3 \mu B / 2 E) \kappa \cdot \xi_{\perp}$, and $\kappa$ is the magnetic field line curvature.

We are interested in the resonant response at Alfvén frequencies. Only passing particle transit frequencies are large enough to contribute. Thus to solve Eq. (1), we first let $v_{\|}=$ $\left\langle v_{\|}\right\rangle+\tilde{v}_{\|}$, where $\langle\cdots\rangle$ denotes the orbit average. Since $\left\langle v_{\|}\right\rangle=0$ for trapped particles, the dominant contribution to $\hat{g}$ is from the passing population. Represent the function $J\left(\psi_{p}, \theta, \phi\right)$ by a Fourier series in $\theta, J\left(\psi_{p}, \theta, \phi\right)=\sum_{l} J_{l}\left(\psi_{p}\right) e^{i S_{l}}$ where $S_{l}=n \phi-l \theta$. We use axisymmetry to consider a single toroidal mode number, $\mathrm{n}$.

To lowest order, let $\hat{g}\left(\psi_{p}, \theta, \phi\right)=\sum_{l} g_{l}\left(\psi_{p}\right) e^{i S_{l}}$. In the high frequency limit, $\omega \sim \omega_{t} \gg$ $\omega_{b}$, with $\omega_{t}, \omega_{b}$ the transit and bounce frequencv respectively, we find $g_{l}\left(\psi_{p}\right)=2 F(\bar{\omega}-$ $\left.\omega_{*}\right) J_{l}\left(\psi_{p}\right) /\left(k_{l}\left\langle v_{\|}\right\rangle-\omega\right)$ with $k_{l}=(n q-l) /(q R)$. The final form of $\hat{g}$ is then $\hat{g}\left(\psi_{p}, \theta, \phi\right)=2 F\left(\bar{\omega}-\omega_{*}\right) \sum_{l} \frac{J_{l}}{k_{l}\left\langle v_{\|}\right\rangle-\omega} e^{i S_{l}}$.

The dispersion relation can be expressed in a quadratic form ${ }^{3}$ and is given by

$$
D(\omega)=\delta K-\delta W_{f}-\delta W_{k}^{(a)}-\delta W_{k}^{(n a)}=0
$$

where $\delta K=(1 / 2) \omega^{2} \int \rho|\xi|^{2} d^{3} x$ is the kinetic energy and

$$
\delta W_{f}=(1 / 2) \int d^{3} \mathbf{x}\left\{\left|\delta \mathbf{B}_{\perp}\right|^{2}+\left|2 \kappa \cdot \xi_{\perp}\right|^{2} B^{2}\right.
$$


$\left.+\left(\mathbf{J} \cdot \mathbf{B} / B^{2}\right)\left(\delta \mathbf{B}_{\perp} \times \mathbf{B}\right) \cdot \xi_{\perp}^{*}-2\left(\kappa \cdot \xi_{\perp}^{*}\right)\left(\nabla P_{c} \cdot \xi_{\perp}\right)\right\}$

is the potential energy due to the core plasma (fluid). The kinetic contributions are

$\delta W_{k}^{(a)}=-\int d^{3} \mathbf{x}\left(\kappa \cdot \xi_{\perp}^{*}\right)\left(\nabla P_{h} \cdot \xi_{\perp}\right)$

which is the adiabatic part of the energetic particle potential energy, and

$\delta W_{k}^{(n a)}=-(1 / 2) \int d^{3} \mathbf{x}\left(\delta \hat{p}_{\perp}-\delta \hat{p}_{\text {Phys. Lett. }}\right)\left(\kappa \cdot \xi_{\perp}^{*}\right)$,

which is the non-adiabatic part of the energetic particle potential energy. The perturbed pressure due to the non-adiabatic part is given by $\delta \hat{p}_{\perp}=\int d^{3} \mathrm{v} \hat{g} \mu B$ and $\delta \hat{p}_{\text {Phys. Lett. }}=$ $2 \int d^{3} v \hat{g}(E-\mu B)$.

Using the $\hat{g}$ found above, we find

$\delta W_{k}^{(n a)}=-2 \int d^{3} \mathbf{x} d^{3} \mathbf{v} F E\left(\bar{\omega}-\omega_{*}\right) \sum_{l, l^{\prime}} \frac{J_{l} J_{l^{\prime}}^{*}}{\omega-k_{l}\left\langle v_{\|}\right\rangle} e^{i\left(l^{\prime}-l\right) \theta}$.

Combining the contributions of both co- and counter-passing particles, this reduces to

$\delta W_{k}^{(n a)}=-2 \omega \int d^{3} \mathbf{x} d^{3} \mathbf{v} F E\left(\bar{\omega}-\omega_{*}\right) \sum_{l} \frac{J_{l}^{2}}{\omega^{2}-k_{l}^{2}\left\langle v_{\|}\right\rangle^{2}}$.

Since $P_{h}=\int E F d^{3} \mathbf{v}$ we also get

$\delta W_{k}^{(a)}=-\int d^{3} \mathbf{x} d^{3} \mathbf{v} E F \partial_{\psi_{p}} \log F\left(\kappa \cdot \xi_{\perp}^{*}\right)\left(\nabla \psi_{p} \cdot \xi_{\perp}\right)$

with $\psi_{p}$ the poloidal flux. It is straightforward to verify that $\left|\delta W_{k}^{(a)}\right|,\left|\delta W_{k}^{(n a)}\right| \ll\left|\delta h^{\prime}\right|$ , $\delta W_{f} \mid$ if $\beta_{h} \ll \varepsilon$ and $\rho / R \ll \varepsilon$, which are true in general. We thus assume that the hot particles will not change the MHD eigenmode profile. The calculation of the eigenmode profile has been studied analytically ${ }^{6}$ and numerically using the NOVA-K code ${ }^{3}$. The code results are used in this paper.

We consider a single low $n$ TAE mode with the two most important poloidal harmonics, i.e. $n=1 ; m=1,2$. The sum in Eq. (8) then consists of four terms, with $l=m \pm 1$. The dispersion relation is 
$\left(-\omega^{2}+\omega_{0}^{2}\right) \int \rho|\xi|^{2} d^{3} x+\delta W_{k}^{(a)}+\delta W_{k}^{(n a)}=0$

where $\omega_{0}=v_{A} /\left(2 q_{r} R\right)$ is the eigenmode frequency, $v_{A}$ is the Alfvén velocity and $q_{r}=1.5$ for the mode chosen. One can solve this equation for the frequency using a complex root finder. However, in this case, due to the small contribution from the alpha particles, it is equally accurate to find the roots using a perturbative method.

Let $\omega=\omega_{r}+i \omega_{i}, K=\int \rho\left|\xi_{\perp}\right|^{2} d^{3} \mathrm{x}$. We then find

$\left\{\begin{array}{l}\omega_{r}=\omega_{0}+\frac{1}{2 \omega_{0} K}\left[\delta W_{k}^{(a)}+\operatorname{Re}\left\{\delta W_{k}^{(n a)}\right\}\right] \\ \omega_{i}=\frac{1}{2 \omega_{0} K} \operatorname{Im}\left\{\delta W_{k}^{(n a)}\right\}\end{array}\right.$

Assume the fluid density profile is $\rho\left(\psi_{p}\right)=\rho_{0} F_{i}\left(\psi_{p}\right)$ where $\rho_{0}$ is the central ion density and $F_{i}$ is the ion density distribution function, we find $K=\rho_{0} \int F_{i}\left(\psi_{p}\right)|\xi|^{2} \mathcal{J} d \psi_{p} d \theta d \zeta$ with $\mathcal{J}$ the Jacobian.

A Hamiltonian guiding center code ${ }^{8,9}$ ORBIT is used to evaluate $\delta W_{k}^{(a)}$ and $\delta W_{k}^{(n a)}$. Bounce averages are conveniently converted to time integrals.

Write the particle density in terms of the distribution function $d N=F d^{3} x d^{3} \mathbf{v}$, and use the Monte-Carlo representation for the density (integrated over $\theta$ and $\zeta$ ) $d N=c \sum_{k} \delta\left(\psi_{p}-\right.$ $\left.\psi_{p k}\right) \delta\left(\mu-\mu_{k}\right) \delta\left(E-E_{k}\right) d \psi_{p} d \mu d E$. Normalize F through $\beta_{h}=8 \pi\left(B^{2} V\right)^{-1} \int E d N$ where $V$ is the volume. The density element in the Monte-Carlo representation is then given by

$F d^{3} \mathbf{x} d^{3} \mathbf{v}=\frac{B^{2} V \beta_{h}}{8 \pi \sum_{j} E_{j}} \sum_{k} \delta\left(\psi_{p}-\psi_{p k}\right) \delta\left(\mu-\mu_{k}\right) \delta\left(E-E_{k}\right) d \psi_{p} d \mu d E$.

Substituting $F$, we get

$\delta W_{k}^{(n a)}=\left.\frac{B^{2} V \beta_{h}}{4 \pi \sum_{j} E_{j}} \omega \sum_{k} E_{k}\left(\bar{\omega}-\omega_{*}\right) \sum_{m} \frac{J_{m}^{2}}{k_{l}^{2}\left\langle v_{\|}\right\rangle^{2}-\omega^{2}}\right|_{k}$

and

$\delta W_{k}^{(a)}=-\left.\frac{B^{2} V \beta_{h}}{4 \pi \sum_{j} E_{j}} \sum_{k} E_{k} \partial_{\psi_{p}} \log F\left(\kappa \cdot \xi_{\perp}\right)\left(\nabla \psi_{p} \cdot \xi_{\perp}\right)\right|_{k}$

where $\left.\right|_{k}$ means the function is evaluated at $\psi_{p}=\psi_{p, k}, E=E_{k}, \theta=\theta_{k}, \ldots$, etc.

In order to calculate $\delta \hat{W}_{k}$ we need to know both $\partial_{E} \log F$ and $\partial_{\psi_{p}} \log F$. This cannot be done directly if each particle is represented as a point in phase space. Assigning each 
particle an extended size in both real and velocity space using a Lorentz form gives a very accurate evaluation in test cases using known distribution functions.

Ten thousand particles are used in the simulations. Each particle is advanced in time according to the guiding center equations. Once a particle hits the wall, it is removed. Although we neglect the Larmor radius, we keep all the particle dynamics, including the orbit width. In fact, the latter is much more important than the former since it can significantly modify the mode-particle interaction ${ }^{4}$. The initial spatial distribution is Gaussian and we use a slowing-down distribution in energy. The distribution is uniform in pitch angle $\lambda=v_{\|} / v$ and uniform in poloidal angle $\theta$.

We assume that the mode structure does not change except for the amplitude and phase as time evolves. The mode is initially given an amplitude too small to modify the particle distribution and then advanced in time according to the complex frequency $\omega(t)$ as determined by the dispersion relation. The time interval $\Delta t$ for determination of $\omega$ through solution of the dispersion relation must be chosen small enough so that $\omega \Delta t \ll 1$.

Additional damping $\gamma_{d}$, due to collisions or the continuum can be easily added. We first study the worst case scenario, with damping only provided by the hot particle distribution.

We solve the dispersion relation every 10 transits (one transit $=2 \pi R / v$ ) which in our case is much longer than the bounce time. Then we advance the mode by using the new frequency and growth rate. We have performed simulations with parameters typical for the Tokamak Fusion Test Reactor (TFTR) and for the International Thermonuclear Experimental Reactor (ITER). The radial width of the Gaussian alpha particle distribution is varied over a range from $1 / 5$ to $1 / 3$ of the minor radius. Other profile shapes also produce equivalent results. We use volume average alpha particle beta of $3 \%$ in ITER and $0.2 \%$ in TFTR.

From the numerical results the mode saturation mechanism and the particle loss mechanism are easily understood. Resonant particles which lose energy to the mode through inverse Landau damping move outwards. Thus the density gradient, which is the source of the free energy to drive the wave, decreases as time evolves. Also the particle energy gradient becomes steeper, since high energy particles lose energy whereas low energy particles 
do not interact with the mode, so the mode further loses drive due to the increased velocity space Landau damping and eventually saturates. We find for ITER for a variety of initial profiles that the mode saturates before it becomes large enough to induce particle loss. The maximum linear growth rate is $0.2 \%$ of the mode frequency. In Fig. 1 are shown sample saturation results. The maximum value is $\delta B / B \sim 2 \times 10^{-4}$ and the total losses are unobservable. As in the case of the fishbone, the mode produces additional profile modification before it can decay away, resulting in a strong decay rate. Even so, the profile broadening is very slight, as it involves only the high energy part of the distribution. The time scale for the profile modification by the mode is orders of magnitude shorter than the time scale for alpha particle replenishment, so the additional source of new alpha particles would not modify this result.

For TFTR with no additional damping the mode continues to grow until extensive alpha particle loss is produced. We observe more than $20 \%$ loss in the undamped case. The linear growth rate is $0.1 \%$ of the mode frequency. However, estimates of additional damping ${ }^{10-12}$ are larger than this, so the mode should not be destabilized by alpha particles unless very low damping conditions are produced. Even so it is interesting to analyze the loss mechanism observed in the undamped case, as high energy particles produced by ion cyclotron heating or neutral beam injection can produce more strongly unstable cases.

The stability results can be understood from a simple analysis. From Eq. 7 the growth rate $\gamma$ is proportional to $\left(\bar{\omega}-\omega_{*}\right)$. Using the approximate form of the distribution function $F \sim E^{-3 / 2} e^{-\left(r / L_{n}\right)^{2}}$, we find $\gamma \sim\left[\left(a / L_{n}\right)^{2}-\Delta^{2}\right]$ with $\Delta=\sqrt{3 m_{\alpha} \Omega \omega a^{2} /(4 E)}$ and $m_{\alpha}$ the mass and $\Omega$ the gyro frequency. From $E=0.5 m_{\alpha} \omega^{2} / k_{\|}^{2}$ with $k_{\|} \simeq(n-m / q) / R$, we find $\Delta=3.9$ for ITER, and $\Delta=1.6$ for TFTR. Without additional collisional or continuum damping mode stabilization in TFTR does not occur until the alpha profile has a width comparable to the minor radius.

The mode frequency remains very close to the linear TAE mode frequency $\omega_{0}$ while the growth rate is very small compared with $\omega_{0}$, thus the perturbative method used is a very reasonable approximation. The mode growth rates obtained in this work agree with those 
given by the NOVA-K code ${ }^{3}$.

The dominant loss mechanism is that of barely counter-passing particles losing energy to the wave, transfering into fat banana orbits, and then hiting the outside wall in the co-moving direction. The losses are thus very effective for large banana width. In TFTR all such barely trapped particles are lost whereas in ITER they remain in the device and contribute to mode damping.

It is easy to verify that a lost barely trapped particle has an average pitch $\lambda \simeq$ $\sqrt{1-B_{\min } / B_{\max }} \simeq \sqrt{2 r / R}$, which is in good agreement with the simulation. This result as well as the total observed number of lost particles also agrees with a previous study ${ }^{1}$ of TAE induced loss, which however did not include a self consistent calculation of the mode stabilization. Note that as soon as particles become trapped the resonance with the mode becomes very weak. This contrasts significantly with the fishbone case, where a trapped particle can remain in resonance as it is moved radially outwards to the wall.

With strong mode destabilization such as might be provided by neutral beam injection, large losses would occur in TFTR and should lead to "explosive pulsations" ${ }^{7}$. A more extensive analysis of such a case, including lost particle deposition profiles, etc. will be examined in a future publication. But expected alpha particle densities are not sufficient to destabilize the mode. In the alpha particle driven case in ITER even without additional damping the particle response is local and sufficient to modify the local gradients, thereby stabilizing the mode, but not sufficient to cause losses. The possibility of several $n$ values simultaneously unstable will be considered in a future publication, but the loss mechanism is weak enough that we do not expect serious losses due to alpha particles even in this case.

Our results are similar to the partial results obtained by using a three-dimensional hybrid gyrokinetic--MHD code ${ }^{13}$ MH3D in which at least 200 thousand particles were necessary to overcome the random noise (local particle effects influence the fluid elements).

In summary, the interaction of a single toroidal mode number TAE mode with energetic alpha particles has been investigated self-consistently by using a realistic dispersion relation. We retain all important poloidal harmonics and their radial mode profiles. A Hamiltonian 
guiding center code is used to provide a fast and accurate way to calculate the bounce averaged expressions entering in the dispersion relation. The study includes the particle banana orbit width, nonlinear particle dynamics and the mode-particle interaction. In ITER mode saturation is observed through the flattening of the real space density gradient and the steepening of the energy gradient. The mode amplitude saturates at a level which is too small to induce loss. We do not expect these results to be changed by the effects of magnetic well and plasma shape, as they have little effect on transit frequency phenomena.

We are grateful G. Y. Fu for useful discussions. This work was supported by the U.S. Department of Energy under contract number DE-AC02-76-CHO3073. 


\section{REFERENCES}

1. D. J. Sigmar, C. T. Hsu, R. B. White, and C. Z. Cheng, Phys. Fluids B 4 (6), 1506 (1992).

2. C. Z. Cheng, Fusion Technology 18, 443 (1990).

3. C. Z. Cheng, Phys. Reports 211, 1 (1992).

4. G. Y. Fu, C. Z. Cheng, and K. L. Wong, Phys. Fluids B 5, 4040 (1993).

5. G. Y. Fu and C. Z. Cheng, Phys. Fluids B 4, 3722 (1992).

6. C. Z. Cheng and M. S. Chance, Phys. Fluids 29, 3695 (1986).

7. H. L. Berk, B. N. Breizman, and H. Ye, Phys. Fluids B 5, 1506 (1993).

8. R. B. White and M. S. Chance, Phys. Fluids 27, 2455 (1984).

9. R. B. White and Y. Wu, Numerical evaluation of high energy particle effects in magnetohydrodynamics, Submitted to Journal of Plasma Physics, 1994.

10. F. Zonca and L. Chen, Phys. Rev. Lett. 68, 592 (1992).

11. M. N. Rosenbluth, H. L. Berk, J. W. VanDam, and D. M. Lindberg, Phys. Rev. Lett. 68, $596(1992)$.

12. C. Z. Cheng, G. Y. Fu, H. E. Mynick, R. V. Budny, R. B. White, S. J. Zweben, C. T. Hsu, D. J. Sigmar, D. A. Spong, B. A. Carreras, and C. L. Hedrick, Proceedings of the Fourteenth International Conference on Plasma Physics and Controlled Nuclear Fusion Research, International Atomic Energy Agency, Vienna, 1993 2, 51 (1993).

13. G. Y. Fu and W. Park, Bull. Am. Soc. 38, 1945 (1993). 


\section{FIGURES}

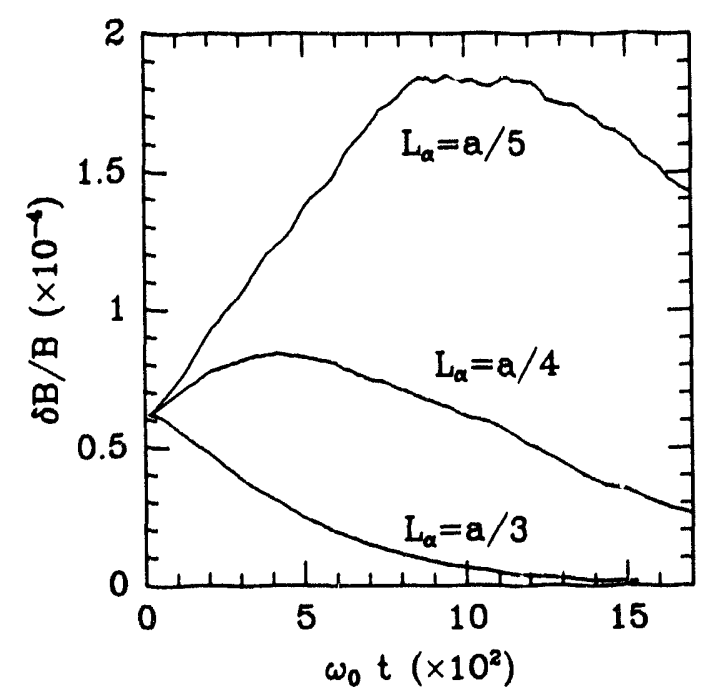

Fig. 1. TAE mode amplitude $\delta B / B\left(\times 10^{-4}\right)$ versus time for ITER with a $3 \%$ alpha particle beta. Three different distribution widths $L_{\alpha}$ are shown. 
Dr. F. Paoloni, Univ. of Wollongong, AUSTRALIA

Prof. M.H. Brennan, Univ. of Sydney, AUSTRALIA

Plasma Research Lab., Australian Nat. Univ., AUSTRALIA

Prof. I.R. Jones, Flinders Univ, AUSTRALIA

Prot. F. Cap, Inst. for Theoretical Physics, AUSTRIA

Prof. M. Heindler, Institut für Theoretische Physik, AUSTRIA

Prot. M. Goossens, Astronomisch Instituut, BELGIUM

Ecole Royale Militaire, Lab. de Phy. Plasmas, BELGIUM

Commission-Eurcpean, DG. XII-Fusion Prog., BELGIUM

Prof. R. Bouciqué, Rijksuniversiteit Gent, BELGIUM

Dr. P.H. Sakanaka, Instituto Fisica, BRAZIL

Prof. Dr. I.C. Nascimento, Instituto Fisica, Sao Paulo, BRAZIL Instituto Nacional De Pesquisas Espaciais-INPE, BRAZIL

Documents Office, Atomic Energy of Canada Ltd., CANADA

Ms. M. Morin, CCFMTokamak de Varennes, CANADA

Dr. M.P. Bachynski, MPB Technologies, Inc., CANADA

Dr. H.M. Skarsgard, Univ. of Saskatchewan, CANADA

Prof. J. Teichmann, Univ. of Montreal, CANADA

Prof. S.R. Sreenivasan, Univ. of Calgary, CANADA

Prof. T.W. Johnsten, INRS-Energie, CANADA

Ur. R. Bolton, Centre canadien de fusion magnétique, CANADA

Dr. C.R. James, Univ. of Alberta, CANADA

Dr. P. Lukác, Komenského Universzita, CZECHO-SLOVAKIA

The Librarian, Culham Laboratory, ENGLAND

Library, R61, Rutherford Appleton Laboratory, ENGLAND

Mrs. S.A. Hutchinson, JET Library, ENGLAND

Dr. S.C. Sharma, Univ. of South Pacific, FIJI ISLANDS

P. Mähönen, Univ. of Helsinki, FINLAND

Prof. M.N. Bussac, Ecole Polytechnique, FRANCE

C. Mouttet, Lab. de Physique des Milieux lonisés, FRANCE

J. Radet, CEN/CADARACHE - Bat 506, FRANCE

Prof. E. Economou, Univ. of Crete, GREECE

Ms. C. Rinni, Univ. of loannina, GREECE

Preprint Library, Hungarian Academy of Sci., HUNGARY

Dr. B. DasGupta, Saha Inst. of Nuclear Physics, INDIA

Dr. P. Kaw, Inst. for Plasma Research, INDIA

Dr. P. Rosenau, Israel Inst. of Technology, ISRAEL Librarian, International Center for Theo Physics, ITALY Miss C. De Palo, Associazione EURATOM-ENEA , ITALY

Dr. G. Grosso, Istituto di Fisica del Plasma, ITALY

Prof. G. Rostangni, Istituto Gas lonizzati Del Cnr, ITALY
Dr. H. Yamato, Toshiba Res \& Devel Center, JAPAN

Prof. I. Kawakami, Hiroshima Univ., JAPAN

Prof. K. Nishikawa, Hiroshima Univ., JAPAN

Librarian, Naka Fusion Research Establishment, JAERI, JAPAN

Director, Japan Atomic Energy Research Inst., JAPAN

Prof. S. Itoh, Kyushu Univ., JAPAN

Research Info. Ctr., National Instit. for Fusion Science, JAPAN

Prof. S. Tanaka, Kyoto Univ., JAPAN

Library, Kyoto Univ., JAPAN

Prof. N. Inoue, Univ. of Tokyo, JAPAN

Secretary, Plasma Section, Electrotechnical Lab., JAPAN

S. Mori, Technical Advisor, JAERI, JAPAN

Dr. O. Mitarai, Kumamoto Inst. of Technology, JAPAN

Dr. G.S. Lee, Korea Basic Sci. Ctr., KOREA

J. Hyeon-Sook, Korea Atomic Energy Research Inst., KOREA

D.I. Choi, The Korea Adv. Inst. of Sci. \& Tech., KOREA

Prof. B.S. Liley, Univ. of Waikato, NEW ZEALAND

Inst of Physics, Chinese Acad Sci PEOPLE'S REP. OF CHINA

Library, Inst. of Plasma Physics, PEOPLE'S REP. OF CHINA

Tsinghua Univ. Library, PEOPLE'S REPUBLIC OF CHINA

Z. Li, S.W. Inst Physics, PEOPLE'S REPUBLIC OF CHINA

Prof. J.A.C. Cabral, Instituto Superior Tecnico, PORTUGAL

Prof. M.A. Hellberg, Univ. of Natal, S. AFRiCA

Prof. D.E. Kim, Pohang inst. of Sci. \& Tech., SO. KOREA

Prof. C.I.E.M.A.T, Fusion Division Library, SPAIN

Dr. L. Stenflo, Univ. of UMEA. SWEDEN

Library, Royal Inst. of Technology, SWEDEN

Prof. H. Wilhelmson, Chalmers Univ. of Tech., SWEDEN

Centre Phys. Des Plasmas, Ecole Polytech, SWITZERLAND

Bibliotheek, Inst. Voor Plasma-Fysica, THE NETHERLANDS

Ass... Prof. Dr. S. Cakir, Middle East Tech. Univ., TURKEY

Dr. V.A. Glukhikh,Sci. Res. Inst. Electrophys.I Apparatus, USSR

Dr. D.D. Ryutov, Siberian Branch of Academy of Sci., USSR

Dr. G.A. Eliseev, I.V. Kurchatov Inst., USSR

Librarian, The Ukr.SSR Academy of Sciences, USSR

Dr. L.M Kovrizhnykh, Inst. of General Physics, USSR

Kernforschungsanlage GmbH, Zentralbibliothek, W. GERMANY

Bibliothek, Inst. Für Plasmaforschung, W. GERMANY

Prof. K. Schindler, Ruhr-Universitát Bochum, W. GERMANY

Dr. F. Wagner, (ASDEX), Max-Planck-Institut, W. GERMANY

Librarian, Max-Planck-Institut, W. GERMANY 

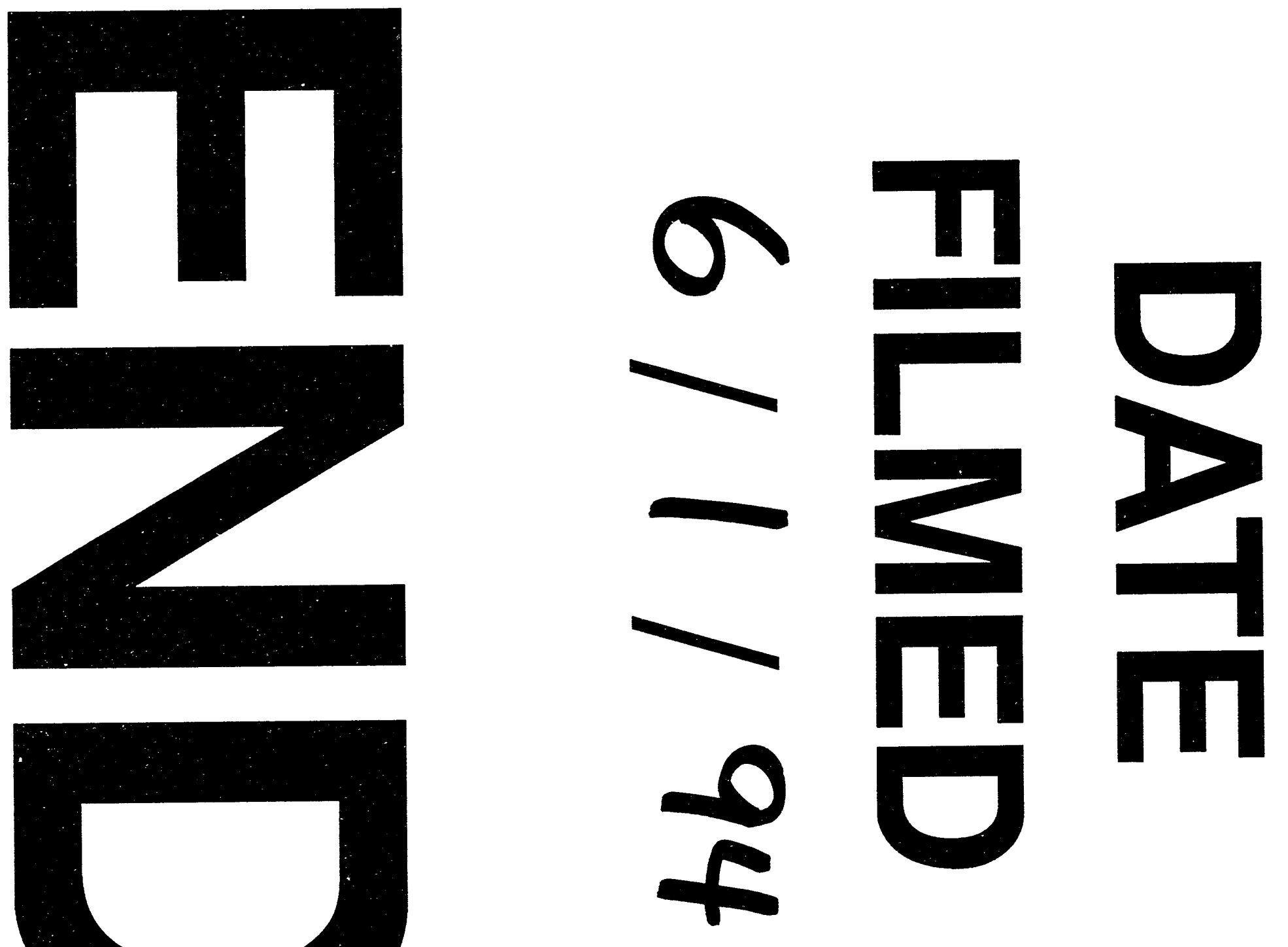
